\title{
DIREITOS HUMANOS, PROCESSOS INTERACIONAIS E VIVÊNCIA ESCOLAR ${ }^{1}$
}

\author{
Dora I. P. da COSTA ${ }^{2}$, Edson do C. INFORSATO ${ }^{3}$ \\ Jéssica G. CONCEIÇÃO ${ }^{4}$, A. S. SOLER ${ }^{5}$ \\ Ligia M. B. BARBOSA ${ }^{6}$, Sheiva A. SÖRENSEN ${ }^{7}$
}

RESUMO: Este trabalho propõe entender as tensões e conflitos provenientes da diversidade cultural existente no âmbito da escola, especialmente, como são tratadas as diversas formas de diferenças e compreender como tais problemas contribuem para a diminuição do desempenho curricular dos alunos. Possui como objetivo geral, realizar ações que contemplem um conjunto de atores sociais que vivenciam o ambiente escolar, tendo como meta a tomada de consciência e a mudança de atitudes por parte destes no que diz respeito à problemática social da discriminação e do preconceito no ambiente escolar. Tem como objetivo específico a produção de material para-didático através da participação dos/as alunos/as e professores/as da escola pública juntamente com a equipe de graduandos (as) da Unesp sobre tipos de preconceitos presentes na escola e possíveis soluções referentes ao respeito à diversidade e diferenças em relação ao Outro. Para seu desenvolvimento utiliza-se uma revisão bibliográfica de livros e artigos sobre o tema discriminação e preconceitos e uma pesquisa de campo a qual está baseada nos parâmetros metodológicos da pesquisa-ação, que inclui a coleta de dados através de questionários, entrevistas, debates e gravações em áudio. Com tais procedimentos tem-se como meta auxiliar e estimular os agentes integrantes da escola a trabalharem e refletirem sobre a temática da discriminação e do preconceito, evitando assim, através da tomada de consciência e do respeito à alteridade e aos direitos humanos, possíveis exclusões, segregações e desenvolvimento de traumas no ambiente escolar.

PALAVRAS-CHAVE: Direitos humanos. Discriminação. Preconceito. Ambiente escolar.

O projeto em questão tem dois desígnios principais. Primeiro, realizar um estudo teórico sobre os temas preconceito e discriminação; segundo, debatê-los com alunos de escola pública e desenvolver ações no sentido de auxiliar a comunidade escolar a superar as dificuldades por estes desencadeadas, tendo como princípio contribuir para a construção de uma cultura calcada nos direitos humanos e na cidadania

\footnotetext{
Esta pesquisa está em andamento e será concluída em dezembro de 2009. Recebe financiamento da PROGRAD/UNESP.

${ }^{2}$ UNESP - Universidade Estadual Paulista. Faculdade de Ciências e Letras - Departamento de Economia. Araraquara - SP - Brasil. 14800-901 - dora@fclar.unesp.br

${ }^{3}$ UNESP - Universidade Estadual Paulista. Faculdade de Ciências e Letras - Departamento de Didática. Araraquara - SP - Brasil. 14800-901 - tamoyo@fclar.unesp.br

${ }^{4}$ Graduanda em Ciências Sociais. UNESP - Universidade Estadual Paulista. Faculdade de Ciências e Letras .Araraquara - SP - Brasil. 14800-901.

${ }^{5}$ Graduanda em Ciências Sociais. UNESP - Universidade Estadual Paulista. Faculdade de Ciências e Letras .Araraquara - SP - Brasil. 14800-901.

${ }^{6}$ Graduanda em Ciências Sociais. UNESP - Universidade Estadual Paulista. Faculdade de Ciências e Letras .Araraquara - SP - Brasil. 14800-901.

${ }^{7}$ Graduanda em Ciências Sociais. UNESP - Universidade Estadual Paulista. Faculdade de Ciências e Letras .Araraquara - SP - Brasil. 14800-901.
} 
Para tanto, partimos da discussão sobre alguns conceitos-chave tais como identidade, preconceito e discriminação à luz da bibliografia recente, definimos a importância do estudo de caso envolvendo a comunidade escolar, propomos a metodologia de trabalho e, por fim, as expectativas advindas da nossa intervenção.

Segundo Stuart Hall (2006), a identidade enquanto conceito possui três acepções, sendo estas decorrentes de contextos históricos específicos. A primeira delas surge com o Iluminismo e apresenta o ser humano como uma entidade unificada que carrega uma essência desde seu nascimento à morte; a segunda, proveniente do final do Século XIX e começo do $\mathrm{XX}$, está relacionada com o sujeito sociológico, aquele que se determina nas interações das quais participa; e a terceira, proveniente da globalização e dos processos que esta desencadeou tais como as migrações e os problemas advindos delas, tem como sujeito aquele capaz de assumir múltiplas identidades, pertencendo a sociedades resultantes da presença da diversidade cultural.

Durval Muniz Albuquerque Júnior discorre sobre a relação do conceito identidade e o preconceito. Na sua análise, a identidade seria um referencial dependente da relação com a alteridade e seria constituída mediante a existência de um ser humano que se coloca em negação ao Outro.

Os grupos humanos, na maioria dos casos, buscaram definir suas identidades a partir do estabelecimento de diferenças em relação aos grupos mais próximos e, quase sempre, aos grupos inimigos, por disputarem o mesmo espaço, os mesmos recursos naturais [...]. (ALBUQUERQUE JÚNIOR, 2007, p.9).

A relação existente entre identidade e preconceito, embora não seja recorrente em todas as situações nas quais se constitui uma identidade, ocorre quando ao definir o Outro, o sujeito o classifica com características por ele tidas como inferiores. Este empreendimento presta-se a afirmar uma suposta superioridade do sujeito em questão e com isso é um dos responsáveis por originar preconceito. Em ótica similar o, “[...] ato de afirmar a identidade e a unidade cultural de um grupo humano implica, muitas vezes, na rejeição de culturas diferentes que potencialmente possam ameaçá-la.” (CARDOSO, 2008, p.16).

Na interação entre identidade e preconceito remete-se a um delineamento deste segundo conceito. Como a palavra já diz, preconceito é um conceito prévio sobre algo do qual não se domina o conhecimento (ALBUQUERQUE JÚNIOR, 2007). Em suas manifestações aparece como um julgamento negativo que se demonstra na forma de um estereótipo. Sobre este último, Albuquerque Júnior (2007, p.13) afirma: 
O discurso da estereotipia é um discurso assertivo, imperativo, repetitivo, caricatural. [...] O estereótipo nasce de uma caracterização grosseira, rápida e indiscriminada do grupo estranho; este é dito em poucas palavras, é reduzido a poucas qualidades que são ditas como essenciais.

Por exemplo, o preconceito contra o brasileiro - mais especificamente o mulato -, muitas vezes, é descrito a partir de um estereótipo que o caracteriza como um povo preguiçoso, sensual e carnavalesco. ${ }^{8}$

Vale ressaltar o caráter sócio-histórico dos preconceitos, pois apesar de serem vistos como naturais, foram construídos através do tempo e de acordo com interesses de grupos que os constituíram e que estavam em conflito. No caso do preconceito contra o negro, Jaime Pinsky (1999) demonstra a frágil sustentação dos argumentos que mostram a raça negra como inferior e proporciona um breve panorama dos fatores que estão nas raízes deste preconceito. De acordo com a obra Somos tod@s iguais, “[...] os preconceitos são realidades historicamente construídas e dinâmicas; são reinventados e reinstalados no imaginário social continuamente.” (CANDAU, 2003, p.17). Em concordância com Pinsky, a autora afirma:

Numa sociedade regida esteticamente por um paradigma branco, conforme o caso brasileiro, a clareza da pele persiste como uma marca simbólica de uma superioridade imaginária, que atua como estratégia de distinção social ou de defesa contra as expectativas colonizadoras da miscigenação. (CANDAU, 2003, p.22).

Definido previamente o conceito de preconceito, resta agora demonstrar a relação deste com o conceito de discriminação. Pinsky e Candau definem a discriminação como a manifestação do preconceito no cotidiano. Em outros termos, a discriminação seria a prática daquilo que se tem por preconceito. Para Candau (2003, p.18) “[...] se o preconceito é fundamentalmente uma atitude, a discriminação refere-se a comportamentos e práticas sociais concretas. Existe uma estreita relação entre os dois conceitos e as realidades a que se reportam.” Enquanto que para Pinsky (1999, p.21)

Quando passamos da idéia à ação, isto é, quando não apenas dizemos que o outro é inferior, mas agimos como se de fato ele o fosse, estamos discriminando as pessoas e os grupos por conta de uma característica que atribuímos a eles.

A pesquisa desenvolvida pelo Ministério da Educação e Cultura (MEC), Instituto Nacional de Estudos e Pesquisas Educacionais (INEP) e pela FIPE (2009) sobre o preconceito

\footnotetext{
${ }^{8}$ Para uma análise detalhada dos preconceitos geográficos referentes ao Brasil ver o capítulo "A formação do Estado Nacional brasileiro e os preconceitos por origem geográfica" na obra de Albuquerque Júnior (2007).
} 
nas escolas brasileiras envolveu 501 escolas e 18.599 participantes. Mostra dados alarmantes sobre o percentual de indivíduos que possuem algum gênero de preconceito. Segundo esta, 99,3\% dos participantes demonstraram possuir algum tipo de preconceito, 96,5\% apresentaram-no em relação a pessoas com necessidades especiais, 94,2\%, referente a diferenças étnico-raciais e, 93,5\%, à questão de gênero. Estes diversos tipos de preconceitos são seguidos pelos de natureza geracional (91,0\%), socioeconômico (87,5\%), de orientação sexual $(87,3 \%)$ e territorial $(75,9 \%)$. Estas conclusões mostram a urgência de se tratar do tema e desenvolver ações e tecnologias sociais para que os efeitos da discriminação e do preconceito sejam atenuados sobre aqueles que se tornam vítimas de mentalidades e ações desintegradoras da coesão social, assim como tratar daqueles que exercem o poder da discriminação e da tortura psicológica.

Hodiernamente, as identidades são cada vez mais múltiplas e ressignificadas, dia a dia, havendo a necessidade de coexistirem de forma integradora em ambientes coletivos. Segue daí que o respeito aos direitos humanos deve ser estimulado a prevalecer nos mais diversos ambientes, de modo que seu estudo e as intervenções sócio-pedagógicas decorrentes preconizam o tratamento não só das identidades em vias de emergência, mas também, das dificuldades relativas ao desempenho escolar, resultantes destes conflitos.

\section{A escola enquanto campo de pesquisa}

A Escola Estadual Dorival Alves ${ }^{9}$ se constitui em locus da pesquisa para o estudo-decaso, pois em conversa com coordenadores e professores percebemos que o problema se apresenta ora latente, ora manifesto no processo de ensino-aprendizagem e nas atividades de lazer. Estudamos autores que trabalham este tipo de problema presente em situação escolar e decidimos focar as experiências relatadas na escola como o meio de identificação das formas de preconceito.

O interesse em compreender a experiência do preconceito originou-se da participação de alunas, integrantes da atual pesquisa no Centro de Ciências de Araraquara (CCA), onde participaram do projeto Consciência Brasileira, na condição de monitoras de uma exposição cujo objetivo era proporcionar noções de cultura, história e geografia sobre as diversas regiões do Brasil, para alunos de ensino fundamental e médio de escolas da rede pública. Nesta ocasião, as pesquisadoras tiveram oportunidade de presenciar manifestações advindas de

\footnotetext{
${ }^{9}$ Agradecemos a colaboração nesta pesquisa dos (as) professores (as) Andréia, Rosana, Márcio, Ricardo, Cássio, Maria das Graças, Ledemur, Anderson, Sandra e dos alunos da tarde e noite.
} 
preconceitos e estereótipos pejorativos relativos a diversos tipos sociais regionais presentes neste evento.

A existência de preconceitos em manifestações sócio-culturais de alunos e integrantes do corpo escolar prejudica a capacidade de convívio e integração de tais agentes, sendo danosos ao processo de aprendizagem, em especial, àqueles que sofrem tais ações, desse modo, este projeto pretende atuar com um conjunto de intervenções que estimulem e auxiliem o corpo escolar a trabalhar a temática, evitando dessa maneira exclusões, segregações, desenvolvimento de traumas, agressões e violações aos direitos humanos.

Tal necessidade é apontada na obra Somos tod@s iguais, na qual explicita como tal processo ocorre.

O cotidiano da escola é palco de diferentes relações sociais e reflete a diversidade cultural presente na sociedade. Assim diferentes visões de mundo, estilos de vida, crenças e costumes, cores, etnia e todos os aspectos que compõem a cultura freqüentam, diariamente, as salas de aula.A instituição escolar representa um microuniverso social, que se caracteriza pela diversidade social e cultural e por, muitas vezes, reproduzir padrões de conduta que permeiam as relações sociais fora da escola. Desse modo, as formas de se relacionar com o outro, na escola, refletem as práticas sociais mais amplas. Podemos dizer que, ainda que valores como igualdade e solidariedade, respeito ao próximo e às diferenças estejam presentes no discurso da escola, outros mecanismos, talvez mais sutis, revelam que preconceitos e estereótipos também integram o cotidiano escolar. (CANDAU, 2003, p.24).

Entende-se então que, sendo a escola um ambiente no qual se encontram pessoas de diferentes culturas, está sujeita a ter problemas de convívio, resultantes do confronto de experiências diversas. Assim, a escola deve buscar estimular a interação social e o respeito às diferenças, uma vez que, ela não representa um mero subproduto da sociedade, e sua função não se resume a apenas reproduzir conhecimentos e valores. A escola e seus membros podem e devem atuar como agentes multiplicadores do processo de construção de cidadania.

Infelizmente - como foi visto nos estudos até então -, manifestações de diferenças ainda desestabilizam o bom andamento da aprendizagem. Portanto, o ensino não é completo enquanto “[...] não levar em consideração a pluralidade de saberes e valores culturais de seu próprio povo.” (CANDAU, 2003, p.28). Para alterar a situação conflituosa é preciso ter a perspectiva de que a escola e o ensino são capazes de mudar de maneira construtiva seu cotidiano.

O preconceito como já definido é fruto de uma realidade histórica e social perversa, logo, para minimizá-lo “[...] é necessário atuar tanto no nível das mentalidades quanto no das situações concretas” (CANDAU, 2003, p.17), para então construir um mundo de maior 
respeito à dignidade humana. Ou, como diz a autora: “Compreender como se dão estes processos é condição imprescindível para desvelá-los e combatê-los, na perspectiva da construção de uma cultura dos direitos humanos.” (CANDAU, 2003, p.18).

\section{Aspectos metodológicos}

A estratégia metodológica escolhida para o desenvolvimento deste estudo foi o da pesquisa-ação relativa ao estudo-de-caso no ambiente escolar (THIOLLENT, 1988), uma vez que se trata de pesquisa social na área de educação, cujo objeto de estudo se constitui nas manifestações discriminatórias dentro da escola, bem como a inclusão de formulações teóricas.

Os procedimentos foram selecionados passo a passo com os professores de cada disciplina, tendo em vista o conteúdo curricular a ser trabalhado. Cada tema selecionado de cada disciplina (história, geografia, português, matemática, física, filosofia e artes) buscou uma integração interdisciplinar de modo a pensar o tema de forma transversal.

Segundo Thiollent (1988, p.75) “[...] com a orientação metodológica da pesquisaação, os pesquisadores em educação, estariam em condição de produzir informações e conhecimentos de uso mais efetivo, inclusive a nível pedagógico [...]”, proporcionando assim condições para a elaboração de ações e intervenções necessárias no ambiente escolar.

Sendo assim, em vez de operacionalizarmos a separação entre observador e observado, vigente nas pesquisas convencionais, a pesquisa-ação deve contribuir para a coparticipação dos pesquisadores e das pessoas envolvidas no problema investigado, sem que tal fato resulte em perda do caráter sistemático e científico do estudo. Tal aproximação a nosso ver contribui para uma formação cidadã tanto dos pesquisadores, quanto dos atores sociais envolvidos no trabalho.

Dentre os recursos metodológicos da pesquisa-ação utilizamos a revisão bibliográfica de livros e artigos que tratam do tema preconceito e discriminação, buscando através desta, apreender os fundamentos teóricos necessários para a elaboração deste trabalho, pois como afirma Thiollent, na pesquisa-ação a teoria deve gerar idéias, hipóteses ou diretrizes para a orientação do estudo. No que diz respeito à coleta de dados, a técnica escolhida consiste nos questionários os quais foram elaborados com linguagem clara e direta, contemplando questões abertas e de múltipla escolha. “Os princípios gerais da elaboração de questionários e formulários convencionais são úteis para que os pesquisadores possam dominar os aspectos técnicos da concepção, da formulação e da codificação.” (THIOLLENT, 1988 p.65). Além 
destes, utilizamos entrevistas individuais com professores, debates com alunos e pesquisa de campo. Todas estas modalidades encontram-se registradas em papel e nas fitas gravadas em áudio.

Para o planejamento das ações em salas de aula, certos cuidados foram tomados para a melhor obtenção do objetivo específico, ou seja, esclarecer os posicionamentos preconceituosos, bem como o desrespeito aos direitos humanos no ambiente escolar. Portanto os materiais e atividades abaixo elencados foram todos adequados segundo a faixa etária dos alunos, ressaltando aspectos lúdicos em cada fase planejada. Recursos audiovisuais como filmes, músicas, obras de arte, atualidades (jornais, revistas e internet) são utilizados mediante discussões, dinâmicas de grupo, além da confecção de material paradidático sobre o assunto. Este último produto da pesquisa é resultado das etapas anteriores vivenciadas pelos alunos, os quais se vêem experimentando no seu cotidiano preconceito, discriminação e posterior superação destas barreiras sociais, através de tomada de consciência e da mudança de atitudes. O meio para se chegar a esta última etapa se dá mediante o envolvimento do alunado com a escrita de narrativas. Os enredos desenvolvidos são publicados em livros e em histórias em quadrinhos, através dos quais os alunos se vêem no cotidiano vivenciando suas histórias de vida, e, finalmente, superando aspectos adversos de suas experiências pessoais.

Uma equipe multidisciplinar de professores trabalha aspectos da língua e expressão (português), as origens dos preconceitos no Brasil (história), apontados pelos alunos no seu cotidiano, técnicas de teatro e expressão coreográfica (artes), representação matemática através da construção de tabelas e gráficos e as representações metafísicas e construtivistas do conhecimento filosófico e das ciências da natureza.

\section{Considerações finais}

Tendo em vista os motivos que nos impulsionaram ao estudo do preconceito nas escolas e a metodologia que usamos para torná-lo possível, vale destacar os objetivos que pretendemos alcançar.

No intuito de contribuir para um convívio escolar mais harmonioso, baseado no respeito à Declaração dos Direitos Humanos, nosso projeto intenciona despertar nos alunos a percepção do Outro como diferente e ao mesmo tempo semelhante, e que todos nós compartilhamos direitos iguais, minimizando o grau de intolerância e violência que prejudica 
o rendimento escolar, como assinala Leme (2008), os alunos que mais relatam sofrer algum tipo de violência são aqueles que se vêem com baixo desempenho.

Como solução para a questão da violência e, conseqüentemente, da melhora do rendimento escolar, propomos uma educação cidadã, tal como Novinsky (2008) nos alerta sobre o risco de não se tê-la hoje em dia. As conseqüências podem ser danosas no futuro, tendo em vista o fácil acesso dos jovens às influências negativas, possibilitadas pelos meios eletrônicos, a autora cita um estudo de David Levy no qual se prova que a educação dada aos alemães que se tornaram nazistas durante a Segunda Guerra Mundial foi mais brutalizada do que a daqueles que se tornaram antinazistas.

Nosso objetivo é sensibilizar os alunos e aumentar a percepção destes em relação aos resultados da intolerância, mostrando como eles podem e devem contribuir para uma sociedade mais justa, igualitária e respeitosa aos direitos fundamentais da pessoa.

O método de pesquisa utilizado é essencial para dar certeza aos alunos de que têm potencial o qual pode ser acionado tanto na aprendizagem quanto na atuação como cidadãos. Tal procedimento também incentiva a mudança de valores e a adoção de práticas que garantam o exercício efetivo do $1^{\circ}$ artigo da Declaração Universal Dos Direitos Humanos, no qual, “Todas as pessoas nascem livres e iguais em dignidade e direitos. São dotadas de razão e consciência e devem agir em relação umas às outras com espírito de fraternidade”.

Este projeto tem como meta final auxiliá-los na construção de suas atuações como cidadãos, induzir a reflexão e a construção de narrativas nas quais eles se vêem em processo de superação das adversidades presentes no cotidiano social e escolar.

\section{HUMAN RIGHTS, INTERACTIONS AND SCHOOL EXPERIENCE}

ABSTRACT: The aim of this case-study is to understand the cultural diversity conflicts at school, focusing in the ways of experiencing it. The actions address the school agents who play significant roles as potential multipliers on changing discrimination and prejudice in school and social environment. The methodology employs research-in-action based on Thiollent (2007). The itinerary develops review on bibliography, interviews, inquiry, and debates with students in classroom using videos. Children and teenagers write books where they see themselves as characters who change roles in every-day-life as victims and/or as agents of tortures. We hope to motivate the community to be aware of respecting human rights and avoiding segregation and traumas at school.

KEYWORDS: Human rights. Discrimination. Prejudice. School environment. 
ALBUQUERQUE JÚNIOR, D. M. Preconceito contra a origem geográfica e de lugar: as fronteiras da discórdia. São Paulo: Cortez, 2007.

CANDAU, V. M. (Coord.). Somos tod@s iguais. Rio de Janeiro: DP\&A, 2003.

CARDOSO, C. M. Fundamentos filosóficos da intolerância. In: CARDOSO, C. M. (Org.). Convivência na diversidade: cultura, educação e mídia. São Paulo: Cultura Acadêmica, 2008. p.16-28.

HALL, S. A identidade cultural na pós-modernidade. 11.ed. Rio de Janeiro: DP\&A, 2006.

LEME, M. I. da S. Educação, diversidade e igualdade: violência e convívio escolar. In: CARDOSO, C. M. (Org.). Convivência na diversidade: cultura, educação e mídia. São Paulo: Cultura Acadêmica, 2008. p.107-126.

FUNDAÇÃO INSTITUTO DE PESQUISAS ECONÔMICAS [FIPE]; MINISTÉRIO DA EDUCAÇÃO [MEC]; INSTITUTO NACIONAL DE ESTUDOS E PESQUISAS EDUCACIONAIS ANÍSIO TEIXEIRA [INEP]. Pesquisa sobre preconceito e discriminação no ambiente escolar. [S.l.]: FIPE: MEC: INEP, 2009. Disponível em: $<$ http://portal.mec.gov.br/dmdocuments/diversidade_apresentacao.pdf > . Acesso em: 16 ago. 2009.

NOVINSKY, A. Para um novo conceito de educação. In: CARDOSO, C. M. (Org.). Convivência na diversidade: cultura, educação e mídia. São Paulo: Cultura Acadêmica, 2008. p.77-88.

PINSKY, J. Serviço de negro. In: PINSKY, J. (Org.). 12 faces do preconceito. São Paulo: Contexto, 1999. p.21-29. (Coleção Vivendo a História).

THIOLLENT, M. Metodologia da pesquisa-ação. 4. ed. São Paulo: Cortez, 1988.

\section{BIBLIOGRAFIA CONSULTADA}

CARVALHO, J. M. de. Cidadania no Brasil: um longo caminho. Rio de Janeiro: Civilização Brasileira, 2001. Pontos e bordados. Belo Horizonte: UFMG, 1999. 